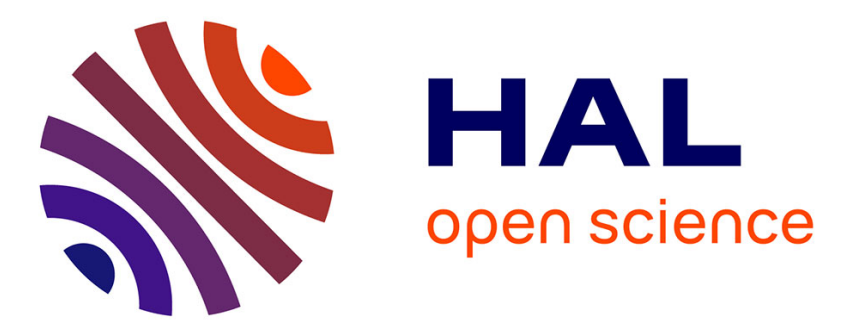

\title{
Serial changes in adiponectin and BNP in ACS patients: paradoxical associations with each other and with prognosis
}

\author{
Donald Sc Ang, Paul Welsh, Pauline H Watt, Scott M Nelson, Allan D \\ Struthers, Naveed Sattar
}

\section{To cite this version:}

Donald Sc Ang, Paul Welsh, Pauline H Watt, Scott M Nelson, Allan D Struthers, et al.. Serial changes in adiponectin and BNP in ACS patients: paradoxical associations with each other and with prognosis. Clinical Science, 2009, 117 (1), pp.41-48. 10.1042/CS20080506 . hal-00488426

\section{HAL Id: hal-00488426 https://hal.science/hal-00488426}

Submitted on 2 Jun 2010

HAL is a multi-disciplinary open access archive for the deposit and dissemination of scientific research documents, whether they are published or not. The documents may come from teaching and research institutions in France or abroad, or from public or private research centers.
L'archive ouverte pluridisciplinaire HAL, est destinée au dépôt et à la diffusion de documents scientifiques de niveau recherche, publiés ou non, émanant des établissements d'enseignement et de recherche français ou étrangers, des laboratoires publics ou privés. 


\title{
Serial changes in adiponectin and BNP in ACS patients: paradoxical associations with each other and with prognosis
}

\author{
Donald SC Ang*, Paul Welsh*, Pauline Watt, Scott M Nelson, Allan Struthers, \\ Naveed Sattar
}

Division of Medicine and Therapeutics, Ninewells Hospital and Medical School, Dundee, Scotland, UK (DA, AS). Division of Cardiovascular and Medical Sciences, Faculty of Medicine, University of Glasgow, Glasgow, Scotland, UK (P Welsh, P Watt, N Sattar). Division of Developmental Medicine, Faculty of Medicine, University of Glasgow, Glasgow, Scotland, UK (SMN).

\section{*Authors contributed equally}

Short Title: Adiponectin, BNP, and acute coronary syndrome

\section{Key words:}

B-type natriuretic peptide; adiponectin; acute coronary syndrome; heart failure; risk markers.

\section{Address for Correspondence:}

Dr Paul Welsh or Professor Naveed Sattar

Both, BHF Cardiovascular Research Building,

Faculty of Medicine,

University of Glasgow,

Glasgow, Scotland, G12 8TA

Email: P.welsh@clinmed.gla.ac.uk or nsattar@clinmed.gla.ac.uk 


\section{ABSTRACT}

Plasma adiponectin is inversely associated with risk of coronary heart disease in healthy people. However, adiponectin and B-type natriuretic peptide (BNP) are both known to be positively associated with risk of poor outcome, and with each other, in acute coronary syndrome (ACS) patients. Serial changes in plasma adiponectin and BNP following ACS have not been assessed previously, and may clarify these apparently paradoxical associations. In this study, adiponectin, BNP, classical risk markers, and clinical parameters were measured on plasma from 442 consecutive ACS patients in an urban teaching hospital, with repeat measures at 7 weeks $(n=338)$. Patients were followed-up for 10 months. Poor outcome was defined as mortality or readmission for ACS or congestive heart failure $(n=90)$. In unadjusted analysis, change in adiponectin (but not baseline or 7 week adiponectin) was significantly associated with risk of adverse outcome: odds ratio (OR) 5.42 (95\% CI 2.78 - 10.55). This association persisted after adjusting for classical risk factors and clinical markers, but was fully attenuated by adjusting for the 7 week BNP measurement $[1.13(0.27$ - 4.92)], which itself remained associated with risk [5.86 (1.04 - 32.94)]. Adiponectin and BNP positively correlated at baseline, 7 weeks, and change in both parameters over 7 weeks also correlated $(r=0.39$, $\mathrm{p}<0.001$ ). In conclusion, increases in plasma adiponectin (rather than absolute levels) after ACS are related to risk of adverse outcome, but this relationship is not independent of BNP levels. Our results allude to a potential direct or indirect relationship between adiponectin and BNP post-ACS that requires further investigation. 


\section{INTRODUCTION}

Adiponectin is a circulating adipokine which has been shown to have the unusual property of correlating inversely with markers of adiposity, including body mass index (BMI) and percentage body fat in epidemiological studies [1]. Adiponectin may have important metabolic regulatory functions [2], and it has also been suggested that it may have some important antiinflammatory properties [3]. In line with this, it may protect cardiac tissue and limit atherogenesis through inflammatory dampening mechanisms [4]. Experimental models in mice show that exogenous administration of adiponectin limits weight gain or even leads to weight loss [5]. In addition, over-expression of adiponectin in the Apo E -/- mouse model reduced atherogenesis [6].

Although plasma adiponectin is clearly linked to lower risk for diabetes (as recently discussed [7]), and an initial study linked low levels of adiponectin to increased risk of coronary heart disease (CHD) events in healthy men [8], a recent meta-analysis suggested a more modest association with CHD [9]. Furthermore, studies in people with prevalent heart failure (CHF) or acute coronary syndromes (ACS) show that high plasma levels of adiponectin are associated with greater disease severity [10;11] and with higher risk of adverse outcome [12;13;14; 15]. Thus, circulating adiponectin concentrations may represent both a protective or harmful signal depending on the context.

B-type natriuretic peptide (BNP) and its inactive NT-terminal metabolite NT-proBNP (released in a 1:1 ratio during processing) are sensitive markers of cardiac overload and are markers of prognosis in those with CHF [16]. Several studies have shown positive correlations of circulating baseline NT-proBNP and BNP with adiponectin in those with prevalent CHF and coronary artery disease $[10 ; 11 ; 12 ; 13 ; 14 ; 15 ; 17 ; 18]$. Indeed, in the recent Atherogene study, baseline adiponectin predicted risk of poor outcome in CHF independent of conventional risk factors, but not independent of BNP [19].

In order to further examine the potential pathological link between BNP and adiponectin, we investigated in 442 ACS patients the inter-relationship of circulating adiponectin and BNP both at baseline and at a seven week follow-up (338 patients). Thus, for the first time, we examined the associations of all these measures to risk of adverse outcomes at 10 months to determine whether change in either parameter was a better predictor of adverse events than a single measurement. We were also able to investigate whether change in one over time correlated with change in the other

\section{MATERIALS AND METHODS Study population}

442 Caucasian patients with the diagnosis of ACS (between August 2004 and November 2006) were consecutively recruited Ninewells Hospital, Dundee. Patients were recruited if they presented within 72 hours after the onset of ischemic discomfort and included those diagnosed with (1) ST elevation MI (STEMI); ST elevation $>1 \mathrm{~mm}$ in 2 limb leads or $>2 \mathrm{~mm}$ in leads V1V6 or new left bundle branch block, (2) Non ST segment elevation MI (NSTEMI); no ST elevation on ECG despite elevated Troponin T >0.01 ug/mL, (3) Unstable angina; ischaemic chest pain lasting more than 30 minutes with no evidence of myocyte necrosis or ST elevation. Ethical approval was obtained from the Tayside Committee of Medical Research Ethics and all participating subjects gave written, informed consent. The research was carried out in accordance with the Declaration of Helsinki.

During the ACS admission, the patients underwent the following clinical procedures:

(1) Clinical history and risk factor analysis 
(2) Evaluation of admission Killip class defined as follow:

- Killip class I: No clinical signs of heart failure.

- Killip class II: Rales or crackles in the lungs, an $S_{3}$ gallop, and elevated jugular venous pressure.

- Killip class III: Frank acute pulmonary oedema

- Killip class IV: Cardiogenic shock or hypotension (measured as systolic BP lower than $90 \mathrm{mmHg}$ ), and evidence of peripheral vasoconstriction (oliguria, cyanosis or sweating).

(3) ECG: presence of absence of ST deviation (>1.0 mm)

(4) Bedside BNP assay

(5) Laboratory tests: admission haemoglobin, eGFR using the modification of diet in renal disease equation and serum Troponin-T level.

(6) Bedside echocardiography: LV systolic dysfunction (LVSD) defined as LVEF <45\%

(Simpson's biplane method) and left ventricular hypertrophy (LVH) assessment.

\section{Echocardiography}

Transthoracic echocardiography was performed by one trained operator (D Ang) using an Acuson (Sequia 512) imaging system with a 3V2C transducer. The scan was performed with the patient lying in the left lateral position at approximately $45 \%$.

\section{Left ventricular hypertrophy assessment}

Patients were studied with two-dimensional guided M-mode echocardiography in standard views. All measurements were made according to the American Society of Echocardiography (ASE) recommendation at end diastole, taken as the onset of QRS complex. The leading edge to leading edge convention was used to measure interventricular septal thickness, left ventricular internal diameter and left ventricular posterior wall thickness. Measurements were made over at least 3 separate cardiac cycles and the average taken. Left ventricular mass was calculated according to the formula of Devereux et al. 0.80 (ASE left ventricular mass) + 0.6 [20] and indexed to body surface area to give a left ventricular mass index (LVMI). Left ventricular hypertrophy was defined as LVMI greater than $95 \mathrm{~g} / \mathrm{m}^{2}$ in females and greater than $115 \mathrm{~g} / \mathrm{m}^{2}$ in males in accordance to ASE guidelines [21].

\section{Left ventricular systolic function assessment}

Quantitative assessment of LV systolic function was made using the modified biplane Simpson's method to calculate a LVEF. Three measurements from successive cardiac cycles were made in the two chamber and four chamber views. LVSD was defined as an LVEF < $45 \%$.

\section{Blood sample collection and analysis}

Samples were collected by venipucture into EDTA vacutainer tubes or serum clot accelerators. One EDTA vacutainer of blood sample was kept at room temperature and analysed for BNP within 4 hours of the draw time. Whole blood was analysed with the triage BNP assay (Biosite, USA) as reported previously [22]. The inter-assay CV was $8.8 \%$ at $71.3 \mathrm{pg} / \mathrm{mL}$ and $11.6 \%$ at $4088 \mathrm{pg} / \mathrm{mL}$. The detection limit was $5 \mathrm{pg} / \mathrm{mL}$. An electrochemilumninescent immunoassay approved for quantitative measurement of Troponin $\mathrm{T}$ was provided by Roche Diagnostics and run on Roche Modular E170 unit. At $0.06 \mathrm{ug} / \mathrm{L}$ a CV of $10 \%$ is achievable and the detection limit was $0.01 \mathrm{ug} / \mathrm{L}$. Blood samples for adiponectin or other non-routine analyte measurement were spun at $2000 \mathrm{~g}$ for $15 \mathrm{~min}$ and the serum or plasma layers were aliquoted within 4 hours, snap frozen, and stored at $-80^{\circ} \mathrm{C}$. Total plasma adiponectin was analysed using a commercially 
available kit (R\&D systems, Oxon, UK). The inter-assay CV for the adiponectin assay was less than $8 \%$. The same methods were used for samples at follow-up measurements.

\section{Follow-up Measurements}

7 weeks after baseline admission, an attempt was made to re-examine patients with a full ECG, transthoracic echocardiography to assess LVEF, and routine blood tests including repeat bedside BNP and freezing of plasma samples (average time of follow-up $52 \pm 17$ days). Of the 442 baseline patients (of whom 90 experienced adverse outcomes by 10 months), 433 were still alive, and 338 consented to continuing participation in the study at 7 weeks (of whom 51 experienced adverse outcomes by 10 months). In relating BNP and adiponectin levels to risk of outcome we used all 442 baseline patients for whom measurements were obtained, and the 338 patient samples available to us from the 7 week measurement

\section{End points}

The end point of death from any cause, readmission with ACS or admission with congestive heart failure (CHF) was evaluated at 10 months (265.79 \pm 80.31 days). Information on end points was collected from telephone interviews with patients or patient relatives, hospital database and patients case notes. The definition of readmission with ACS is as described above. Congestive heart failure was defined as hospitalization for a clinical syndrome involving at least 2 of the following: paroxysmal nocturnal dyspnoea, orthopnoea, elevated jugular venous pressure, pulmonary crackles, third heart sound and cardiomegaly or pulmonary oedema on chest X-Ray. These clinical signs and symptoms must have represented a clear change from the normal clinical status, requiring intravenous diuretics, inotropic support or vasodilator therapy.

\section{Statistical analysis}

Continuous variables are summarized as median and 25 th and 75 th percentile. For discrete variables, absolute and relative frequencies per category are given. Variables were logarithmically transformed to obtain normal distributions, with tertiles of adiponectin generated. Inter-group differences were assessed by chi squared test or analysis of variance. Spearman correlation coefficients are reported. The association of adiponectin with adverse outcome was examined in different binary logistic regression models, first a univariate model, then in a model adjusting for classical risk factors, a third model additionally adjusted for baseline BNP and a fourth model for 7 week BNP. Goodness of fit of the models was tested by Hosmer-Lemeshow. Statistical significance was determined at $\mathrm{p}<0.05$.

\section{RESULTS}

\section{Baseline characteristics}

In the complete patient group the median BNP level at baseline was $154 \mathrm{pg} / \mathrm{ml}$ (inter-quartile range [IQR] 53-336), and the median baseline adiponectin level was $6.76 \mu \mathrm{g} / \mathrm{ml}$ (IQR 4.1610.82). With continuous analyses, the baseline correlation between BNP and adiponectin was $\mathrm{r}=0.32,(\mathrm{p}<0.001)$.

Table 1 illustrates baseline characteristics of the patients according to tertiles of adiponectin concentration. As expected, age increased across tertiles of adiponectin ( $p$ for trend $<0.001$ ). Some other major cardiovascular risk factors showed inverse associations with adiponectin including proportion of male gender $(\mathrm{p}<0.001)$, BMI $(\mathrm{p}<0.001)$, and total cholesterol $(\mathrm{p}=0.07)$ while HDL cholesterol increased across tertiles $(\mathrm{p}<0.001)$. Blood pressure, presence of hypertension, diabetes, or smoking habit showed no significant association with adiponectin levels. Haemoglobin levels and kidney function (eGFR) decreased across adiponectin tertiles $(\mathrm{p}<0.001)$. Among clinical measures, left ventricle ejection fraction $(\mathrm{p}<0.001)$ decreased, and 
sub-optimal prognosis according to Killip class increased $(\mathrm{p}=0.004)$ with increasing adiponectin.

\section{Changes in adiponectin and BNP from baseline to 7 weeks}

The median BNP level at 7 weeks was 94pg/ml (IQR 36-198) and the median adiponectin level was $5.49 \mu \mathrm{g} / \mathrm{ml}$ (IQR 3.48-8.99). With continuous analyses the 7 week correlation between $\mathrm{BNP}$ and adiponectin was $\mathrm{r}=0.33$, $(\mathrm{p}<0.001)$.

Overall change in adiponectin and BNP levels between baseline and 7 week follow up for the whole patient group are shown in Fig $\mathbf{1} \mathbf{a}$ and $\mathbf{b}$ respectively. As can be seen from these figures both the change in adiponectin and BNP were near-normally distributed, with the former being slightly left-skewed and the latter right-skewed (skewedness statistic -1.22 and 1.80 respectively). For both biomarkers there was a spread of patients with either increases or decreases in either marker over the 7 week interval. Figure 2 (with both markers logtransformed to normality) demonstrates a significant correlation between changes in BNP versus change in adiponectin. Indeed the correlation $(r=0.39, p<0.001)$ was at least as strong as the baseline and 7 week correlations between parameters noted above.

\section{Associations of baseline adiponectin and BNP with adverse outcome}

In unadjusted models, baseline adiponectin showed a borderline significant association with outcome: OR 2.06 (95\% CI 0.92-4.63) p=0.08 (Table 2a). Adjusting for classical risk factors (including clinical parameters) attenuated the association (OR 1.63 [0.54 - 4.93]). Subsequent adjustments for BNP levels attenuated the association of baseline adiponectin with risk to near unity. As seen in Table $\mathbf{2 b}$ however, BNP remained significantly associated with poor outcome in every adjustment model, even after adjusting for baseline adiponectin (OR 3.26 [1.54 $6.91])$.

\section{Associations of 7 week adiponectin and BNP with adverse outcome}

Among those who survived the first 7 weeks following ACS and who consented to further study, the association between 7 week adiponectin and risk of poor outcome was not considerably different to the association seen at baseline, and none was significant, perhaps due to reduced power with fewer observations (Table 2a). In contrast, the association of 7 week BNP with risk of poor outcome was substantially stronger, and was independent of classical risk factors, and independent of 7 week adiponectin (OR 6.84 [2.54 - 18.45]) (Table 2b).

\section{Associations of change in adiponectin and BNP with adverse outcome}

Change in adiponectin (Table 2a), appeared somewhat more strongly linked to risk for adverse outcome than either baseline or 7 week adiponectin. For change in adiponectin the unadjusted OR was $5.42(2.78-10.55)$, and attenuated to OR $3.99(1.79-8.92)$ with adjustment for classical markers, and to OR $3.17(1.29-7.78)$ with additional adjustment for change in BNP. Change in BNP was not itself independently associated with adverse outcome in the latter model, suggesting change in adiponectin was the stronger marker.

Since change in adiponectin and 7 week BNP appeared to have the strongest independent associations with outcome, we included both markers in same multivariable model to test whether 7 week BNP could explain the association of change in adiponectin with prognosis. After doing this, change in adiponectin was no longer associated with risk for adverse outcome (OR 1.13 [0.27 - 4.92]), but 7 week BNP measurement remained significantly associated (OR $5.90[1.04-32.94])$. 


\section{DISCUSSION}

To our knowledge, this is the first study to date to examine the association of circulating adiponectin and BNP with risk of poor outcome in a group of ACS patients where serial measurements have been made. Importantly, an increase in adiponectin 7 weeks after admission was more strongly associated with risk of adverse outcome than a single measure at either time point - in other words, if adiponectin levels increased, adverse event risk was greater, whereas the absolute levels of adiponectin at either time point were less important. In contrast, 7 week BNP measurement was more strongly associated with risk, superior to both baseline and change in BNP measurements. In terms of independent risk prediction, the strongest marker of risk of adverse events was 7 week BNP, which was associated with risk independently of change in adiponectin. Finally, although the patterns of risk associations of these markers are different, these data allow us to show that following index admission for ACS, BNP and adiponectin associate with each other at baseline, at follow up, and that change in both markers also correlate $(r=0.39, \mathrm{p}<0.001)$.

Our finding of a positive correlation between baseline circulating BNP and adiponectin, although apparently paradoxical on the basis of presumed functions of adiponectin, was an expected result based on previous findings in similar patient groups $[10 ; 11 ; 12 ; 13 ; 14 ; 15 ; 17$; $18 ; 19]$. Our finding that 7 week BNP is more strongly related to adverse outcome than BNP at admission is in agreement with a recent study in 157 CHF patients, where discharge BNP was shown to be strongly associated with poor outcome [23].

We do not propose that our results definitively answer the question of whether circulating BNP and adiponectin are or are not clinically useful in prognosis of ACS. Rather, our results may give insight into the pathophysiology behind increased risk of ACS recurrence, CHF, or death following an index ACS event. Our results are suggestive of an interesting and potentially important pathphysiological pathway which links an increase in adiponectin to adverse prognosis in a manner not independent of BNP. Although an observational study cannot imply a causal link, it is interesting to speculate on the potential relationship of adiponectin and BNP following ACS.

We found that absolute levels of BNP at 7 weeks were the strongest predictor of prognosis. This makes sense, since levels of BNP following the settling of acute phase response and/or changes in clinical therapies after an event, will better represent long-term cardiac /vascular status, and therefore subsequent risk. In contrast to BNP, increasing levels of adiponectin following index ACS admittance were potentially more strongly related to risk than baseline or 7 week adiponectin, and yet this relationship was dependant on 7 week BNP in multivariable models. This may be suggestive of some association between progressive disease severity and changes in adiponectin (as measured by follow-up BNP). The Atherogene investigators have very recently shown that the relationship of baseline adiponectin with risk of death or non-fatal $\mathrm{MI}$ in a group of coronary artery disease patients is confounded by associations with BNP [19]. Our observations now extend this observation to show that the two parameters also change in parallel post ACS, such that the risk associations of adiponectin with risk are dependant on BNP. This provides evidence that there may be a direct or indirect link between high post ACS $\mathrm{BNP}$ and a rise in adiponectin in those at greatest risk of poor outcome.

If there is a link between the two parameters, are there any clues to mechanisms? Natriuretic peptides may directly stimulate higher adiponectin levels since a novel lipolytic and potential lipid-mobilising effect of natriuretic peptides has been identified [24]. These actions appear to be mediated by specific adipocyte membrane receptors, which operate via a cGMP-dependent pathway and they may indirectly stimulate adiponectin production [24]. Furthermore, infusion 
of atrial natriuretic peptide (carperitide) in patients with heart failure leads to increased adiponectin plasma levels [25]. Alternatively, TNF $\alpha$ (among other pro-inflammatory cytokines) has been suggested to inhibit adiponectin expression in tissue from healthy subjects [26; 27], but perhaps not in obese subjects [28]. TNF $\alpha$ is known to be elevated in conditions such as CHF and ACS [29], and hence, speculatively, the inhibitory signal may also be lost in such patients.

A recent attempt at explaining the physiology behind the reverse epidemiology of adiponectin in patients with ACS and CHF has been made, with the authors suggesting that elevated levels of adiponectin in these cases represent an attempt at counter-regulation of systemic inflammation [30]. Although this is a possibility, the additional possible direct cardiprotective and metabolic roles of adiponectin in ACS and CHF should not be overlooked. Importantly, adiponectin may directly reduce oxidative ischemia-reperfusion injury $[31 ; 32 ; 33]$, perhaps alluding to a mechanism whereby elevated BNP, in response to cardiac injury, induces an adiponectin-mediated cardioprotective response. Interestingly, this may also be true in silent ischaemia since others have suggested elevations in BNP may also occur in silent ischaemia $[34 ; 35]$, an observation potentially explaining why it is a better marker than simple echo measures of cardiac dysfunction. Additionally, from a metabolic viewpoint, ACS and CHF are often considered to be insulin resistant states, although individuals who are insulin resistant without cardiovascular complications would be expected to have low levels of adiponectin. As we recently suggested [11], high levels of adiponectin in those with ACS and CHF may be a reflection of a salvage mechanism to improve insulin resistance and fatty acid oxidation, perhaps at a cost of cachexia in some cases. Regardless of mechanisms, greater cardiac disease severity may lead to a greater cardiological and metabolic salvage attempt and thus higher adiponectin levels. Alternatively, our speculation may be misguided and adiponectin may just be a passive marker of other physiological processes, its actions inhibited by peripheral "adiponectin resistance."

Limitations of the study require consideration. The group of 442 ACS patients went on to have 90 endpoint events, and follow-up measures are based on 51 events in 338 patients, which represents a relatively low power for the study and we cannot discount the possibility of type II errors. Nevertheless, our data on baseline associations of adiponectin with age and female gender [36] as well as with BNP $[10 ; 11 ; 12 ; 13 ; 14 ; 15 ; 17 ; 18 ; 19]$, and the link to endpoints $[19 ; 23 ; 37]$, is consistent with the literature and suggest results are externally valid. Further larger studies with serial measures are required to confirm and expand on the potential mechanistic relationships of adiponectin, BNP, and cardiac stress. In this study we do not focus on the potential clinical utility of any measure of adiponectin or BNP in the ACS clinical setting, but on pathophysiological changes in ACS which may instruct further clinical studies. Of additional interest, the use of genetics (e.g. Mendelian randomisation) may help tease out the whether adiponectin is protective, harmful, or passive for vascular risk for a variety of patient/cohort groups.

In conclusion, we have shown for first time that using serial measurements that an increase in plasma adiponectin after ACS is strongly related to risk of adverse outcome, but that this relationship is not independent of BNP levels. Taken together with evidence of apparently paradoxical correlations of adiponectin and BNP at baseline, follow-up, and in overall change following ACS, our results allude to a potential direct or indirect relationship between adiponectin and BNP post-ACS that requires further investigation. 


\section{Conflicts of Interest}

DA, P Welsh, P Watt, SMN, \& NS have nothing to declare. AS has been a consultant to Stirling Medical Innovations, who manufacture a BNP assay.

\section{Funding}

This work was funded by grants from the British Heart Foundation and Glasgow Royal Infirmary Endowments. 


\section{REFERENCES}

[1] Cnop, M., Havel, P.J., Utzschneider, K.M., Carr, D.B., Sinha, M.K., Boyko, E.J., Retzlaff, B.M., Knopp, R.H., Brunzell, J.D., and Kahn, S.E. (2003) Relationship of adiponectin to body fat distribution, insulin sensitivity and plasma lipoproteins: evidence for independent roles of age and sex. Diabetologia 46 459-69.

[2] Lafontan, M., and Viguerie, N. (2006) Role of adipokines in the control of energy metabolism: focus on adiponectin. Curr. Opin. Pharmacol. 6 580-5.

[3] Ouchi, N., and Walsh, K. (2007) Adiponectin as an anti-inflammatory factor Clin. Chim. Acta. 380 24-30.

[4] Ouchi, N., Shibata, R., and Walsh, K. (2006) Cardioprotection by adiponectin. Trends Cardiovasc. Med. 16 141-6.

[5] Yamauchi, T., Kamon, J., Minokoshi, Y., Ito, Y., Waki, H., Uchida, S., Yamashita, S., Noda, M., Kita, S., Ueki, K., Eto, K., Akanuma, Y., Froguel, P., Foufelle, F., Ferre, P., Carling, D., Kimura, S., Nagai, R., Kahn, B.B., and Kadowaki, T. (2002) Adiponectin stimulates glucose utilization and fatty-acid oxidation by activating AMP-activated protein kinase. Nat. Med. 8 1288-95.

[6] Okamoto, Y., Kihara, S., Ouchi, N., Nishida, M., Arita, Y., Kumada, M., Ohashi, K., Sakai, N., Shimomura, I., Kobayashi, H., Terasaka, N., Inaba, T., Funahashi, T., and Matsuzawa, Y. (2002) Adiponectin reduces atherosclerosis in apolipoprotein Edeficient mice. Circulation 106 2767-70.

[7] Wannamethee, S.G., Lowe, G.D., Rumley, A., Cherry, L., Whincup, P.H., and Sattar, N. (2007) Adipokines and risk of type 2 diabetes in older men. Diabetes Care 30 1200-5.

[8] Pischon, T., Girman, C.J., Hotamisligil, G.S., Rifai, N., Hu, F.B., and Rimm, E.B. (2004) Plasma adiponectin levels and risk of myocardial infarction in men. JAMA 291 1730-7.

[9] Sattar, N., Wannamethee, G., Sarwar, N., Tchernova, J., Cherry, L., Wallace, A.M., Danesh, J., and Whincup, P.H. (2006) Adiponectin and coronary heart disease: a prospective study and meta-analysis. Circulation 114 623-9.

[10] Nakamura, T., Funayama, H., Kubo, N., Yasu, T., Kawakami, M., Saito, M., Momomura, S., and Ishikawa, S.E. (2006) Association of hyperadiponectinemia with severity of ventricular dysfunction in congestive heart failure. Circ. J. 70 155762.

[11] McEntegart, M.B., Awede, B., Petrie, M.C., Sattar, N., Dunn, F.G., MacFarlane, N.G., and McMurray, J.J. (2007) Increase in serum adiponectin concentration in patients with heart failure and cachexia: relationship with leptin, other cytokines, and B-type natriuretic peptide. Eur. Heart J. 28 829-35.

[12] Tsutamoto, T., Tanaka, T., Sakai, H., Ishikawa, C., Fujii, M., Yamamoto, T., and Horie, M. (2007) Total and high molecular weight adiponectin, haemodynamics, and mortality in patients with chronic heart failure. Eur. Heart J. 28 1723-30.

[13] Kistorp, C., Faber, J., Galatius, S., Gustafsson, F., Frystyk, J., Flyvbjerg, A., and Hildebrandt, P. (2005) Plasma adiponectin, body mass index, and mortality in patients with chronic heart failure. Circulation 112 1756-62.

[14] George, J., Patal, S., Wexler, D., Sharabi, Y., Peleg, E., Kamari, Y., Grossman, E., Sheps, D., Keren, G., and Roth, A. (2006) Circulating adiponectin concentrations in patients with congestive heart failure. Heart 92 1420-4.

[15] Cavusoglu, E., Ruwende, C., Chopra, V., Yanamadala, S., Eng, C., Clark, L.T., Pinsky, D.J., and Marmur, J.D. (2006) Adiponectin is an independent predictor of all-cause mortality, cardiac mortality, and myocardial infarction in patients presenting with chest pain. Eur. Heart J. 27 2300-9. 
[16] Clerico, A., and Emdin, M. (2004) Diagnostic accuracy and prognostic relevance of the measurement of cardiac natriuretic peptides: a review. Clin. Chem. 50 33-50.

[17] von Eynatten, M., Hamann, A., Twardella, D., Nawroth, P.P., Brenner, H., and Rothenbacher, D. (2006) Relationship of adiponectin with markers of systemic inflammation, atherogenic dyslipidemia, and heart failure in patients with coronary heart disease. Clin. Chem. 52 853-9.

[18] Tanaka, T., Tsutamoto, T., Nishiyama, K., Sakai, H., Fujii, M., Yamamoto, T., and Horie, M. (2008) Impact of oxidative stress on plasma adiponectin in patients with chronic heart failure. Circ. J. 72 563-8.

[19] Schnabel, R., Messow, C.M., Lubos, E., Espinola-Klein, C., Rupprecht, H.J., Bickel, C., Sinning, C., Tzikas, S., Keller, T., Genth-Zotz, S., Lackner, K.J., Munzel, T.F., and Blankenberg, S. (2008) Association of adiponectin with adverse outcome in coronary artery disease patients: results from the AtheroGene study. Eur. Heart J. 29 649-57.

[20] Devereux, R.B., Casale, P.N., Kligfield, P., Eisenberg, R.R., Miller, D., Campo, E., Alonso, D.R. (1986) Performance of primary and derived M-mode echocardiographic measurements for detection of left ventricular hypertrophy in necropsied subjects and in patients with systemic hypertension, mitral regurgitation and dilated cardiomyopathy. Am. J. Cardiol. 57 1388-93.

[21] Lang, R.M., Bierig, M., Devereux, R.B., Flachskampf, F.A., Foster, E., Pellikka, P.A., Picard, M.H., Roman, M.J., Seward, J., Shanewise, J.S., Solomon, S.D., Spencer, K.T., Sutton, M.S., Stewart, W.J. (2005) Recommendations for chamber quantification: a report from the American Society of Echocardiography's Guidelines and Standards Committee and the Chamber Quantification Writing Group, developed in conjunction with the European Association of Echocardiography, a branch of the European Society of Cardiology. J. Am. Soc. Echocardiogr. 18 1440-63.

[22] Morrison, L.K., Harrison, A., Krishnaswamy, P., Kazanegra, R., Clopton, P., and Maisel, A. (2002) Utility of a rapid B-natriuretic peptide assay in differentiating congestive heart failure from lung disease in patients presenting with dyspnea. J. Am. Coll. Cardiol. 39 202-9.

[23] Cournot, M., Mourre, F., Castel, F., Ferrieres, J., and Destrac, S. (2008) Optimization of the use of B-type natriuretic peptide levels for risk stratification at discharge in elderly patients with decompensated heart failure. Am. Heart J. 155 986-91.

[24] Sengenes, C., Berlan, M., De Glisezinski, I., Lafontan, M., and Galitzky, J. (2000) Natriuretic peptides: a new lipolytic pathway in human adipocytes. Faseb. J. 14 1345-51.

[25] Tanaka, T., Tsutamoto, T., Sakai, H., Nishiyama, K., Fujii, M., Yamamoto, T., and Horie, M. (2008) Effect of atrial natriuretic peptide on adiponectin in patients with heart failure. Eur. J. Heart Fail. 10 360-6.

[26] Bruun, J.M., Lihn, A.S., Verdich, C., Pedersen, S.B., Toubro, S., Astrup, A., and Richelsen, B. (2003) Regulation of adiponectin by adipose tissue-derived cytokines: in vivo and in vitro investigations in humans. Am. J. Physiol. Endocrinol. Metab. 285 E527-33.

[27] Wang, B., and Trayhurn, P. (2006) Acute and prolonged effects of TNF-alpha on the expression and secretion of inflammation-related adipokines by human adipocytes differentiated in culture. Pflugers Arch. 452 418-27.

[28] Degawa-Yamauchi, M., Moss, K.A., Bovenkerk, J.E., Shankar, S.S., Morrison, C.L., Lelliott, C.J., Vidal-Puig, A., Jones, R., and Considine, R.V. (2005) 
Regulation of adiponectin expression in human adipocytes: effects of adiposity, glucocorticoids, and tumor necrosis factor alpha. Obes. Res. 13 662-9.

[29] Mizia-Stec, K., Gasior, Z., Zahorska-Markiewicz, B., Janowska, J., Szulc, A., Jastrzebska-Maj, E., and Kobielusz-Gembala, I. (2003) Serum tumour necrosis factor-alpha, interleukin-2 and interleukin-10 activation in stable angina and acute coronary syndromes. Coron. Artery Dis. 14 431-8.

[30] Rathmann, W., Haastert, B., Herder, C., Hauner, H., Koenig, W., Meisinger, C., Holle, R., and Giani, G. (2007) Differential association of adiponectin with cardiovascular risk markers in men and women? The KORA survey 2000. Int. J. Obes. (Lond) 31 770-6.

[31] Shibata, R., Sato, K., Pimentel, D.R., Takemura, Y., Kihara, S., Ohashi, K, Funahashi, T., Ouchi, N., Walsh, K. (2005) Adiponectin protects against myocardial ischemia-reperfusion injury through AMPK- and COX-2-dependent mechanisms. Nat. Med. 11 1096-103.

[32] Tao, L., Gao, E., Jiao, X., Yuan, Y., Li, S., Christopher, T.A., Lopez, B.L., Koch, W., Chan, L., Goldstein, B.J., Ma, X.L. (2007) Adiponectin cardioprotection after myocardial ischemia/reperfusion involves the reduction of oxidative/nitrative stress. Circulation 115 1408-16

[33] Gonon, A.T., Widegren, U., Bulhak, A., Salehzadeh, F., Persson, J., Sjöquist, P.O., Pernow, J. (2008) Adiponectin protects against myocardial ischaemia-reperfusion injury via AMP-activated protein kinase, Akt, and nitric oxide. Cardiovasc. Res. 78 116-22

[34] Rana, B.S., Davies, J.I., Band, M.M., Pringle, S.D., Morris, A., Struthers, A.D. (2006) B-type natriuretic peptide can detect silent myocardial ischaemia in asymptomatic type 2 diabetes. Heart. 92 916-20

[35] Struthers, A., Lang, C. (2007) The potential to improve primary prevention in the future by using BNP/N-BNP as an indicator of silent 'pancardiac' target organ damage: BNP/N-BNP could become for the heart what microalbuminuria is for the kidney. Eur. Heart. J. 28 1678-82

[36] Balion, C.M., Santaguida, P., McKelvie, R., Hill, S.A., McQueen, M.J., Worster, A., and Raina, P.S. (2008) Physiological, pathological, pharmacological, biochemical and hematological factors affecting BNP and NT-proBNP. Clin. Biochem. 41 231-9.

[37] Vorovich, E.E., Chuai, S., Li, M., Averna, J., Marwin, V., Wolfe, D., Reilly, M.P., and Cappola, T.P. (2008) Comparison of matrix metalloproteinase 9 and brain natriuretic peptide as clinical biomarkers in chronic heart failure. Am. Heart J. 155 992-7. 


\section{FIGURE TITLES}

Figure 1 (a\&b) Dotplots of the untransformed overall change in adiponectin and BNP between baseline observations and follow-up observations 7 weeks later in the patient group.

Figure 2 Correlation of change from baseline at 7 weeks follow-up for adiponectin and B-type natriuretic peptide. Delta values represent (log follow-up value - log baseline value) for both adiponectin and BNP. 
Table 1 Association between admission adiponectin levels (divided into thirds) and baseline characteristics of ACS patients ( $\mathrm{n}=442$ with adiponectin measurement)

\begin{tabular}{|c|c|c|c|c|c|}
\hline \multicolumn{2}{|l|}{ Characteristic } & $\begin{array}{c}\text { Bottom third } \\
0.48-4.85 \mu \mathrm{g} / \mathrm{ml} \\
(\mathrm{n}=147)\end{array}$ & $\begin{array}{c}\text { Middle third } \\
\text { 4.86-8.94 } \mu \mathrm{g} / \mathrm{ml} \\
\quad(\mathrm{n}=148)\end{array}$ & $\begin{array}{c}\text { Top third } \\
\text { 8.95-35.40 } \mu \mathrm{g} / \mathrm{ml} \\
(\mathrm{n}=147)\end{array}$ & p-value* \\
\hline \multicolumn{2}{|l|}{ Age } & $60(12)$ & $66(11)$ & $69(11)$ & $<0.001$ \\
\hline \multicolumn{2}{|c|}{ Sex Male/Female n (\%) } & $125 / 22(85 / 15)$ & $98 / 50(66 / 44)$ & $77 / 70(52 / 48)$ & $<0.001$ \\
\hline \multicolumn{2}{|c|}{ Systolic blood pressure (mmHg) } & $130(115-150)$ & $131(118-150)$ & $128(110-147)$ & 0.23 \\
\hline \multicolumn{2}{|c|}{ Diastolic blood pressure $(\mathrm{mmHg})$} & $70(63-81)$ & $72(65-82)$ & $70(60-80)$ & 0.18 \\
\hline \multicolumn{2}{|c|}{ Total cholesterol (mmol/L) } & $5.12(4.19-6.08)$ & $4.81(3.94-5.95)$ & $4.52(3.85-5.62)$ & 0.07 \\
\hline \multicolumn{2}{|c|}{ HDL cholesterol (mmol/L) } & $1.15(0.99-1.33)$ & $1.32(1.11-1.47)$ & $1.50(1.2-1.82)$ & $<0.001$ \\
\hline \multicolumn{2}{|c|}{$\operatorname{BMI}\left(\mathrm{kg} / \mathrm{m}^{2}\right)$} & $28.0(26.0-31.0)$ & $26.0(24 .-29.0)$ & $25.0(22.0-29.0)$ & $<0.001$ \\
\hline \multirow[t]{3}{*}{ Smoking n $(\%)$} & Never & $46(31)$ & $57(38)$ & $52(35)$ & \\
\hline & Past & $41(28)$ & $44(30)$ & $52(35)$ & \\
\hline & Present & $60(41)$ & $47(32)$ & $43(30)$ & 0.21 \\
\hline \multicolumn{2}{|c|}{ Haemoglobin $(\mathrm{g} / \mathrm{dl})$} & $15.0(14.1-15.8)$ & $14.1(12.7-14.9)$ & $13.3(12.1-14.4)$ & $<0.001$ \\
\hline \multicolumn{2}{|c|}{ eGFR (ml/min/1.73m²) } & $70(59-78)$ & $66(52-75)$ & $61(51-73)$ & $<0.001$ \\
\hline \multicolumn{2}{|c|}{ Troponin T (ng/ml) } & $0.27(0.01-1.86)$ & $0.36(0.06-1.47)$ & $0.31(0.07-1.43)$ & 0.98 \\
\hline \multicolumn{2}{|c|}{ Non ST-elevation ACS (\%) } & 69 & 75 & 75 & 0.353 \\
\hline \multicolumn{2}{|c|}{ Type 2 Diabetes n (\%) } & $21(14)$ & $23(16)$ & $16(11)$ & 0.48 \\
\hline \multicolumn{2}{|c|}{ History of hypertension (\%) } & $61(41)$ & $71(48)$ & $74(50)$ & 0.29 \\
\hline \multicolumn{2}{|c|}{ ST deviation on ECG n (\%) } & $73(50)$ & $68(46)$ & $71(48)$ & 0.81 \\
\hline \multicolumn{2}{|c|}{ LBBB on ECG n $(\%)$} & $4(2.7)$ & $5(3.4)$ & $7(4.8)$ & 0.63 \\
\hline \multicolumn{2}{|c|}{ LV ejection fraction (\%) } & $57(49-63)$ & $55(45-62)$ & $52(39-61)$ & 0.001 \\
\hline \multicolumn{2}{|c|}{ LV hypertrophy (\%) } & & $81(71)$ & $74(67)$ & 0.680 \\
\hline \multicolumn{2}{|c|}{ Killip class 2, 3 or $4 \mathrm{n}(\%)$} & & $13(9)$ & $25(17)$ & 0.004 \\
\hline BNP (pg/mL) & & $81(39-216)$ & $152(44-343)$ & 239 (114-489) & $<0.001$ \\
\hline
\end{tabular}

ACS, acute cornary syndrome; eGFR, endothelial glomerular filtration rate; LBBB, Left bundle branch block; LV, left ventricular

Data presented are the number $(\%)$ of patients or median and $25^{\text {th }} / 75^{\text {th }}$ inter-quartile range (IQR) for continuous variables.

p-values represent trends across adiponectin thirds 
Table 2a Association (Odds ratio) between baseline adiponectin, 7 week adiponectin, and change in adiponectin and collective adverse outcomes of mortality, heart failure or acute coronary syndrome $(\mathrm{n}=51)$ within 10 months of index acute coronary syndrome events.

\begin{tabular}{|c|c|c|c|}
\hline \multirow[b]{2}{*}{ Adjustment model } & \multicolumn{3}{|c|}{ Adiponectin measurement } \\
\hline & $\begin{array}{c}\text { Baseline } \\
\text { adiponectin }\end{array}$ & $\begin{array}{c}7 \text { Week } \\
\text { adiponectin }\end{array}$ & $\begin{array}{l}\text { Change in } \\
\text { adiponectin }\end{array}$ \\
\hline Unadjusted & $2.06(0.92-4.63)$ & $2.19(0.79-6.08)$ & $5.42(2.78-10.55)$ \\
\hline Classical risk factors & $1.63(0.54-4.93)$ & $1.31(0.33-5.27)$ & $3.99(1.79-8.92)$ \\
\hline $\begin{array}{l}\text { Classical risk factors }+ \\
\text { baseline BNP }\end{array}$ & $1.18(0.38-3.64)$ & - & \\
\hline $\begin{array}{l}\text { Classical risk factors }+7 \\
\text { week BNP }\end{array}$ & - & $0.74(0.17$ & - \\
\hline $\begin{array}{l}\text { Classical risk factors and } \\
\text { change in BNP }\end{array}$ & - & & $3.17(1.29-7.78)$ \\
\hline
\end{tabular}


Table 2b Association (Odds ratio) between baseline BNP, 7 week BNP, and change in BNP and collective adverse outcomes of mortality, heart failure or acute coronary syndrome $(n=51)$ within 10 months of index acute coronary syndrome events.

\section{BNP measurement}

\begin{tabular}{lccc}
\cline { 2 - 4 } Adjustment model & Baseline BNP & 7 Week BNP & Change in BNP \\
\hline Unadjusted & $4.29(2.59-7.11)$ & $6.73(3.33-13.60)$ & $2.33(1.13-4.82)$ \\
Classical risk factors & $2.83(1.35-5.92)$ & $6.54(2.49-17.21)$ & $3.07(1.25-7.53)$ \\
Classical risk factors + & $3.26(1.54-6.91)$ & - & \\
baseline adiponectin & & & \\
Classical risk factors +7 & - & $6.84(2.54-18.45)$ & - \\
week adiponectin & &
\end{tabular}

ORs for adiponectin and BNP are for $1 \log$ unit increase in the patient population.

Classical risk factors = Age, sex, BMI, pre-existing hypertension, pre-existing diabetes mellitus, Killip class 2,3 or 4, ST deviation, left bundle branch block, log troponin on admission, CKD stages 3, 4 or 5, left ventricular systolic dysfunction, smoking status, haemoglobin on admission, total and HDL cholesterol concentrations. 
Figure $1(\mathbf{a} \& b)$
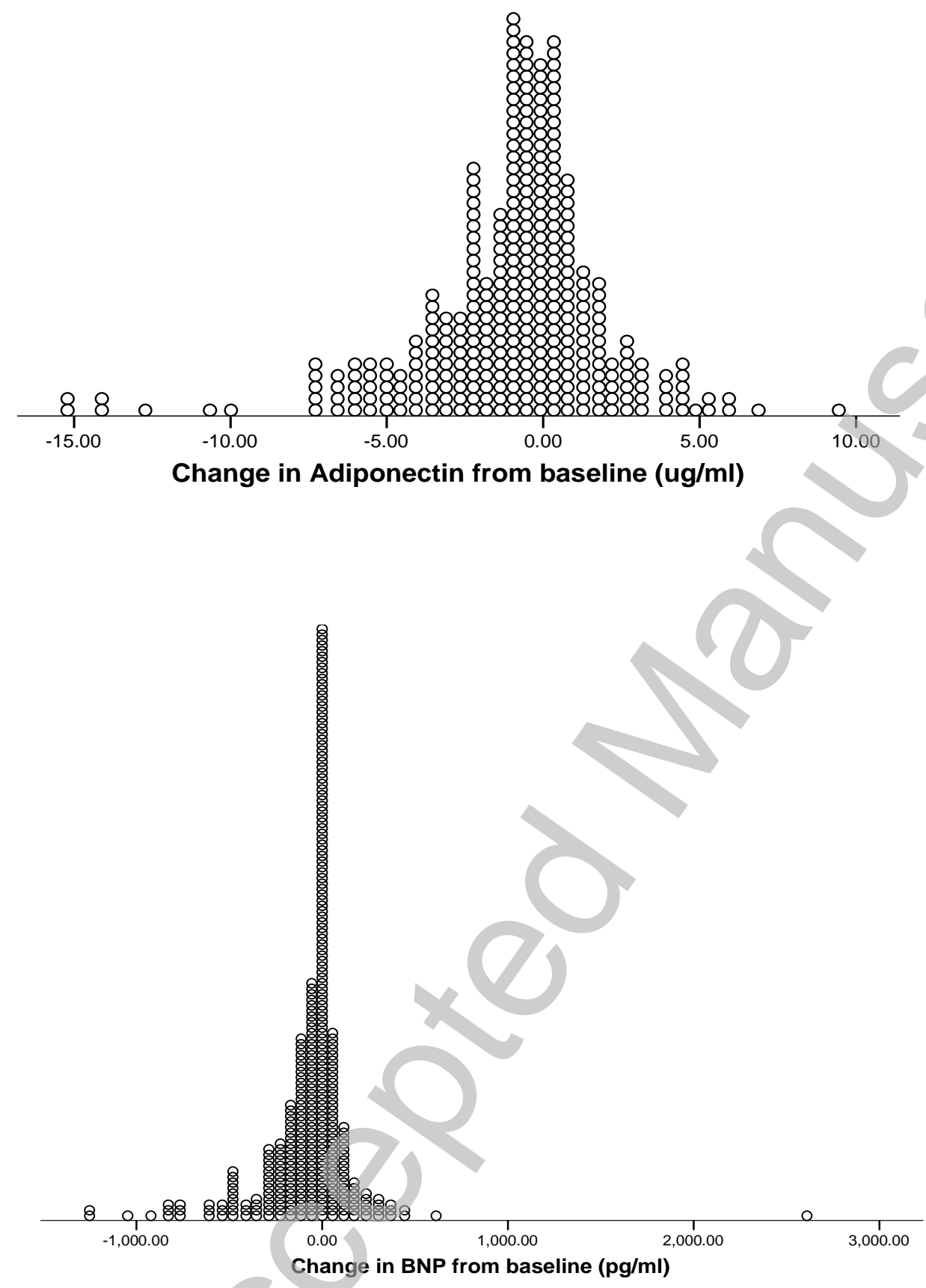


\section{Figure 2}

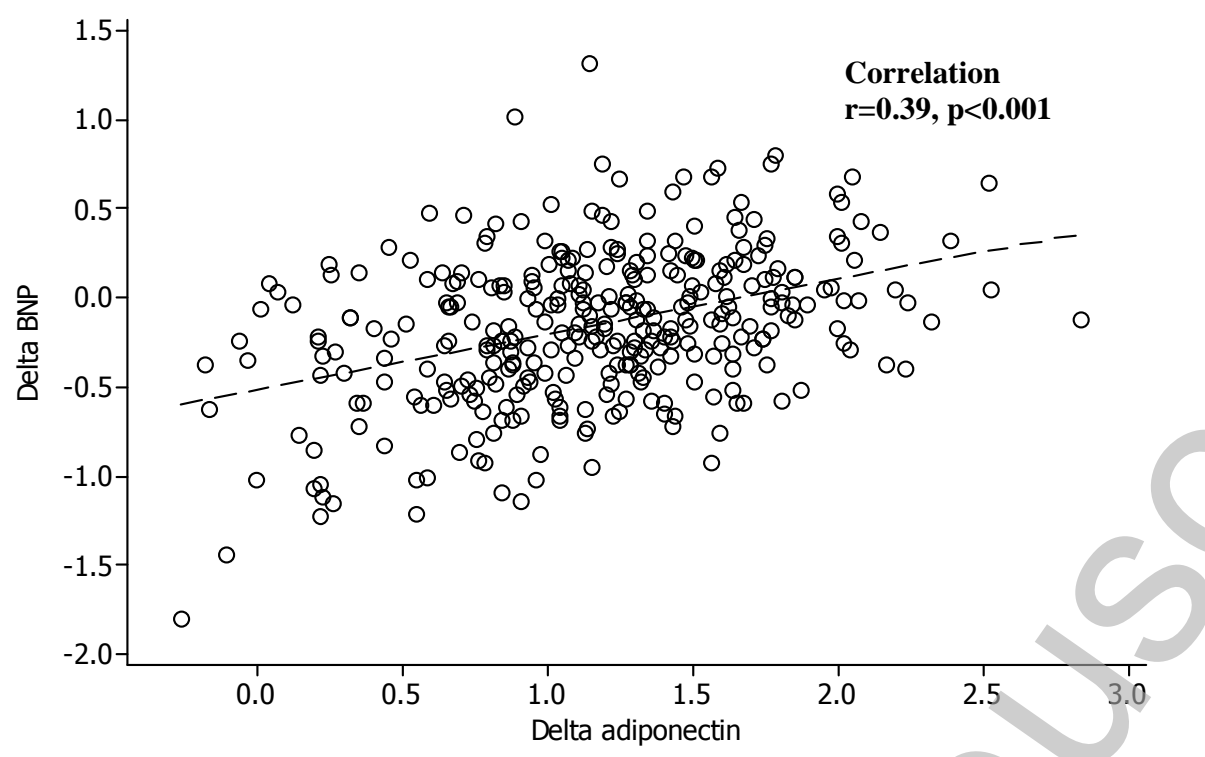

